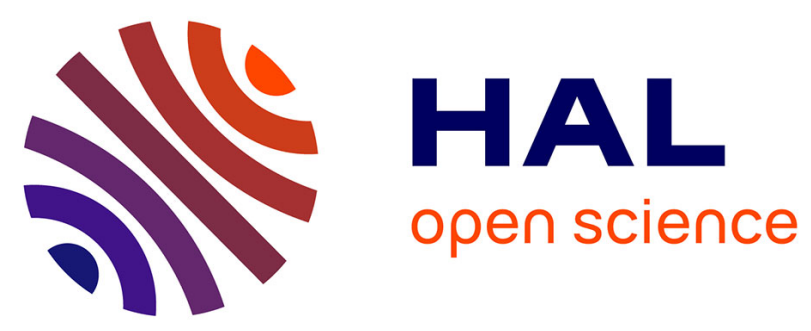

\title{
Spectrum of point mutations and genomic rearrangements in high-risk breast/ovarian cancer Chilean families
}

Patricio Gonzalez-Hormazabal, Sara Gutierrez-Enriquez, Daniel Gaete, Jose M. Reyes, Octavio Peralta, Enrique Waugh, Fernando Gomez, Sonia Margarit, Teresa Bravo, Rafael Blanco, et al.

\section{To cite this version:}

Patricio Gonzalez-Hormazabal, Sara Gutierrez-Enriquez, Daniel Gaete, Jose M. Reyes, Octavio Peralta, et al.. Spectrum of point mutations and genomic rearrangements in high-risk breast/ovarian cancer Chilean families. Breast Cancer Research and Treatment, 2010, 126 (3), pp.705-716. 10.1007/s10549-010-1170-y . hal-00583559

\section{HAL Id: hal-00583559 \\ https://hal.science/hal-00583559}

Submitted on 6 Apr 2011

HAL is a multi-disciplinary open access archive for the deposit and dissemination of scientific research documents, whether they are published or not. The documents may come from teaching and research institutions in France or abroad, or from public or private research centers.
L'archive ouverte pluridisciplinaire HAL, est destinée au dépôt et à la diffusion de documents scientifiques de niveau recherche, publiés ou non, émanant des établissements d'enseignement et de recherche français ou étrangers, des laboratoires publics ou privés. 
TITLE PAGE

\section{SPECTRUM OF BRCA1/2 POINT MUTATIONS AND GENOMIC REARRANGEMENTS IN HIGH-RISK BREAST/OVARIAN CANCER CHILEAN FAMILIES}

Patricio Gonzalez-Hormazabal (1); Sara Gutierrez-Enriquez (2)(3); Daniel Gaete (1); Jose M Reyes (4); Octavio Peralta (4)(5); Enrique Waugh (6); Fernando Gomez (6); Sonia Margarit (7); Teresa Bravo (8); Rafael Blanco (1); Orland Diez (2)(9) * \#; Lilian Jara (1) *\#.

(1) Human Genetics Program, Institute of Biomedical Sciences (ICBM), School of Medicine, University of Chile. Av. Independencia 1027, P.O. Box 70061, Santiago, Chile

(2) Vall d'Hebron Institute of Oncology (VHIO), Barcelona, Spain

(3) Medical Oncology Program, Vall d'Hebron University Hospital Research Institute, Barcelona, Spain

(4) Clínica Las Condes, Santiago, Chile

(5) Department of Ginaecology and Obstetrics, School of Medicine, University of Chile. Av Santa Rosa 1234. Santiago, Chile.

(6) Clínica Santa María. Santiago, Chile

(7) School of Medicine and Clínica Alemana, Universidad del Desarrollo. Santiago, Chile.

(8) National Cancer Society (Corporación Nacional del Cáncer-CONAC-). Santiago, Chile

(9) Oncogenetics Laboratory. University Hospital Vall d'Hebron, Barcelona, Spain

* These author contributed equally to this work

\# Corresponding authors:

Lilian Jara, Ph. D,

Human Genetics Program, Institute of Biomedical Sciences (ICBM),

School of Medicine, University of Chile,

Av. Independencia 1027, P.O. Box 70061, Santiago, Chile;

Phone:+56-2-9786458;

Fax: +56-2-7373158;

e-mail: 1jara@med.uchile.cl

Orland Diez, Ph. D,

Oncogenetics Laboratory

Molecular Medicine and Genetics Program

University Hospital Vall d'Hebron

Institute of Oncology (VHIO)

Passeig Vall d'Hebron 119-129

08035 Barcelona

Spain

e-mail: odiez@ vhebron.net 
ABSTRACT

The distribution of $B R C A 1 / 2$ germline mutations in breast/ovarian cancer (BC/OC) families varies among different populations. In the Chilean population there are only two reports of mutation analysis of BRCA1/2 and these included a low number of $\mathrm{BC}$ and/or OC patients. Moreover, the prevalence of BRCA1/2 genomic rearrangements in Chilean and in other South American populations is unknown. Here we present the mutation-detection data corresponding to a set of 326 high-risk families analyzed by conformation-sensitive gel electrophoresis and heteroduplex analysis. To determine the contribution of BRCA1/2 LGRs in Chilean BC patients, we analyzed 56 high-risk subjects with no pathogenic BRCA1/2 point mutations. Germline BRCA1/2 point mutations were found in $23(7.1 \%)$ of the 326 Chilean families. Families which had at least 3 BC and/or OC cases showed the highest frequency of mutations (15.9\%). We identified 14 point pathogenic mutations. Three recurrent mutations in BRCA1 (c.187_188delAG, c.2605_2606delTT, and c.3450_3453delCAAG) and three in BRCA2 (c.4969_4970insTG, c.5374_5377delTATG, and c.6503_6504delTT) contributed to 63.6\% and 66.7\% of all deleterious mutations of each gene, that may reflect the presence of region-specific founder effects. Taken together BRCAl/2 recurrent point mutations account for $65.2 \%$ (15/23) of the BRCA1/2(+) families. No large deletions or duplications involving BRCA1/2 were identified in a subgroup of 56 index cases negative for BRCAl/2 point mutations. Our study, which is the largest conducted to date in a South American population, provides a comprehensive analysis on the type and distribution of BRCAl/2 mutations and allelic variants.

Keywords: Breast cancer. BRCA1/2. Chilean population. LGRs. recurrent mutations 


\section{INTRODUCTION}

Breast cancer (BC) is the most common cancer among women worldwide. It has been established that one out of eight women will develop BC during their lives [1]. In Chile, mortality in women due to BC has risen, from 8.5 deaths per 100,000 women in 1985 to 12.8 per 100,000 women in 1995 [2]. Currently, it has the second-highest mortality rate among cancers (13.8/100,000 women) [3]. Incidence increased from 16.2/100,000 women in 1998 to 26.2/100,000 women in 2002 [4].

Hereditary BC accounts for 5-15\% of all BC cases [5]. Together, germline mutations in the two major susceptibility genes BRCA1 and BRCA2 (BRCA1/2) account for approximately $20 \%$ of familial BC cases [6]. Carriers of mutations in any of these genes have a $40-85 \%$ cumulative lifetime risk of BC by the age of 70 . Studies of BRCA1/2 mutation frequencies have revealed significant differences in populations of different geographic regions and ethnicities. Disease-causing mutations are distributed throughout the entire coding regions of both genes. Since the identification of BRCA1 and BRCA2 as the principal genes responsible for inherited BC [7, 8], more than 3,400 distinct DNA sequence variants have been described in the BIC database (http://research.nhgri.nih.gov/bic/), of which 1,625 can be classified as pathogenic, including 1,454 truncating mutations (1,075 frameshift and 379 nonsense) and 139 splicing alterations. The remaining mutations, including 1,351 distinct missense changes, are unclassified variants of uncertain clinical consequences. In addition to point mutations that can be detected within a PCR fragment, BRCA1 and BRCA2 are both known to have germline mutations resulting from Large Genomic Rearrangements (LGRs) that result in duplications or deletions of one or more exons, usually producing premature stop codons.

Little is known about the contribution of BRCA1/2 to hereditary BC in South American populations. In the Chilean population there are only two reports of mutation analysis of $B R C A 1 / 2$, and these included a low number of $\mathrm{BC}$ and/or ovarian cancer (OC) patients $[9,10]$. Moreover, the prevalence of BRCA1/2 genomic rearrangements in Chilean and in other South American populations is unknown. Here we present the mutation-detection data corresponding to a set of 326 high-risk families analyzed by conformation-sensitive gel electrophoresis and heteroduplex analysis. Results of 64 out of these 326 high risk families were previously reported [9] showing that the BRCAl/2 gene mutation spectrum was heterogeneous and broad. Our current study, which is the largest conducted to date in a South American population, provides a comprehensive analysis on the type and distribution of BRCA1/2 mutations and allelic variants. To determine the contribution of BRCAl/2 LGRs in Chilean BC patients, we analyzed 56 high-risk subjects with no pathogenic BRCA1/2 point mutations.

\section{METHODS}

\section{Families}

In this study, 326 high-risk BC/OC Chilean families were selected from the files of the Servicio de Salud del Area Metropolitana de Santiago, Corporación Nacional del Cáncer (CONAC) and other private services in the Metropolitan Area of Santiago. Pedigrees were constructed on the basis of an index case considered to have the highest probability of being a deleterious mutation carrier. None of the families met the strict criteria for other known syndromes involving BC, such as $\mathrm{Li}$ Fraumeni, ataxia-telangiectasia, or Cowden disease. All families participating in the study self reported Chilean ancestry dating several generations, after extensive interviews with several members of each family from different generations.

Table 1 shows the specific characteristic of the families selected according to the inclusion criteria. In the sample of selected families, 15.3\% (50/326) had bilateral BC, 9.0\% (29/326) had BC and OC, and 2.8\% (9/326) presented male BC. From the 326 families which participated in this study, 348 women had only BC, two had both BC and OC, 5 had OC, and 7 had male BC. BC and OC for all cases included in the study were verified using the original pathology report. 
This study was approved by the Institutional Review Board of the School of Medicine of the University of Chile. Informed consent was obtained from all the participants.

\section{BRCA1 and BRCA2 mutation analysis}

Genomic DNA was extracted from peripheral blood lymphocytes of 362 index cases belonging to the 326 high-risk selected families. Samples were obtained according to the method described by Chomczynski and Sacchi [11].

The whole coding sequences and exon-intron boundaries of the BRCA1 and BRCA2 genes were analyzed for sequence variants using conformational-sensitive gel electrophoresis according to described protocols [9]. Any fragment showing a mobility shift was directly sequenced in both directions. Sequencing was performed in an ABI prism 3100 automated fluorescence-based cycle sequencer (Applied Biosystems, USA) and a rhodamine dye terminator system (Applied Biosystems, USA).

Multiplex Ligation-Dependent probe Assay (MLPA) was performed for screening LGRs in a subgroup of 56 index cases negative for BRCA1/2 point mutations. MLPA analysis was performed according to manufacturer instructions (MRC Holland, Holland) using the SALSA MLPA Kit P002-B1 for BRCA1 and SALSA MLPA Kit P045-B1 for BRCA2. The fragments obtained were analyzed by capillary electrophoresis using an ABI3130-xl Genetic Analyzer (Applied Biosystems, USA) with a $36 \mathrm{~cm}$ capillary array and POP-7 polymer (Applied Biosystems, USA). GeneMapper 4.0 software (Applied Biosystems, USA) was used for fragment analysis and the results (peak size, height and areas) were exported to an Excel data sheet to calculate the relative peak area. Normalization was achieved by dividing the intra-normalized peak area by the average intra-normalized probe ratio of all analyzed samples in the same round of analysis.

\section{Mutation nomenclature}

Mutations are described at the cDNA level according to the Human BRCA1 reference sequence: accession U14680; and the Human BRCA2 reference sequence: accession U43746; from GenBank sequence database (http://www.ncbi.nlm.nih.gov/genbank/). The BRCAl and BRCA2 numbering for the BIC traditional mutation nomenclature is based on reference sequences as stated above where the A of the ATG translation initiation codon is at position 120 of BRCA1 and position 229 of BRCA2. The Human Genome Organization (HUGO) systematic nomenclature for the description of sequence variants in DNA and protein sequences [12] follows the rule in which the A of the ATG translation initiation codon is +1 . 


\section{RESULTS}

The BRCA1 and BRCA2 genes of 362 index cases belonging to 326 high-risk unrelated families were scanned for mutations. We identified a total of fourteen point pathogenic mutations (seven in BRCAl and seven in BRCA2) (Tables 3 and 4). Furthermore, we identified 14 variants of unknown significance (6 in BRCA1 and 8 in BRCA2) (Table 5) and 28 polymorphisms (17 in BRCA1 and 11 in BRCA2) (Table 6). According to the type of mutation, small deletions leading to frameshifts were more frequent $(n=11)$, followed by splicing mutations $(n=1)$, insertions $(n=1)$ and a missense pathogenic mutation. No large deletions or duplications involving BRCA1/2 were identified in a subgroup of 56 index cases negative for $B R C A 1 / 2$ point mutations.

\section{BRCA1/2 pathogenic point mutations}

Germline BRCA1/2 point mutations were found in $23(7.1 \%)$ of the 326 Chilean families (Table 2). Despite the low frequency of pathogenic point mutations detected in this series, the families that had at least $3 \mathrm{BC}$ and/or OC cases showed the highest frequency of mutations (15.9\%). The frequency was lower for families with $2 \mathrm{BC}$ cases (6.6\%), and two out of the nine families (22.2\%) with one $\mathrm{BC}$ case and one OC case were carriers of pathogenic mutations. No BRCA1/2 pathogenic mutations were identified in the group of 57 (17.5\%) early-onset BC patients ( $<35$ years) reporting no first or second degree relatives affected with BC or OC (Table 2). It is probable that in this group BC is due to moderate or low penetrance genes and not to BRCA1/2 mutations.

In the sample of 326 Chilean families, our group identified 14 point pathogenic mutations. Nine have been previously reported by our group [9], four by other groups, and one was a new mutation not previously described. Nevertheless, it is important to emphasize that two of the previously reported mutations c.3977_3980delTGAG (BRCA1) and c.8296delGT (BRCA2) have only two and one records in the BIC database, respectively. The frameshift c. 3977_3980delTGAG was identified in a Chilean family (F203), which only presented two cases of female BC diagnosed at age 36 (index case) and at age 40 (bilateral BC). The father of the index case was diagnosed with prostate cancer at age 50 (Table 3). We obtained a DNA sample only from the index case who was carrier of the aforementioned mutation. This mutation has only two records in the BIC database, one of them in an Asian population. The c.8292delGT mutation has only one record in the BIC database. This mutation was found in family F93, a BC/OC cancer family containing two BC cases diagnosed at ages 26 (index case) and 32, and one $\mathrm{OC}$ at 60 . We only analyzed the index case and four healthy relatives (a sister, a brother and two cousins), and only the index case was a carrier of the c.8296delGT mutation.

Four of the 14 distinct pathogenic mutations found by our group were novel. To our knowledge, these have not been reported in the BIC database or elsewhere. Three of them were reported in our previous study and to date have not been reported in other studies (c.2605_2606delTT [BRCA1]; c.4185_4188delCAAG [BRCA1]; c.5667delT [BRCA2]) [9], and c.9490delG (BRCA2) is a new novel mutation. The BRCA2 c.9490delG mutation was identified in only one BC/OC family (F211). The family presented three $\mathrm{BC}$ cases, two of them diagnosed under the age of 50, and one $\mathrm{OC} / \mathrm{BC}$ diagnosed at age 42/50. This mutation was found in the index case (OC/BC) and in her sister affected with $\mathrm{BC}$ at age 38 . This mutation is located in exon 25 and generates a stop at codon 3088, deleting 9\% of the protein. The deleted segment includes a DNA binding domain with unique structural features for binding ssDNA and dsDNA.

Three recurrent mutations in BRCA1 (c.187_188delAG, c.2605_2606delTT, and c.3450_3453delCAAG) and three in BRCA2 (c.4969_4970insTG, c.5374_5377delTATG, and c.6503_6504delTT) contributed to 63.6\% and 66.7\% of all deleterious mutations of each gene, which may reflect the presence of region-specific founder effects. The most frequent mutation of BRCA1 was c.3450_3453delCAAG, found in three BRCAl(+) families $(27.3 \%)$, whereas c.5374_5377delTATG was the most 
prevalent alteration in BRCA2 (found in four families, 33.3\%). Taken together, BRCA1/2 recurrent point mutations account for $65.2 \%(15 / 23)$ of the $B R C A 1 / 2(+)$ families.

\section{Variants of unknown significance}

Six BRCA1 variants of the missense type were detected in five different families (Table 5). Of these, five were described in our previous report [9]. In BRCA2 we found eight variants of unknown significance. Seven correspond to missense variants, some of which are described in our previous report [9]. In 12 of the 13 families, the variants of unknown significance were present in the BC cases; in only one family (F14) the variant was detected in a healthy relative. In 9 of the 13 families, we obtained a DNA sample from healthy relatives only. In family F239, the mother with BC was a carrier of variant c.8381T >C , but her daughter who also had BC was not a carrier. The families who were carriers of variants of unknown significance did not present pathogenic mutations in the BRCA1/2 genes. The only exception was F65, which presented the c.IVS17-1G>A mutation (BRCA1). In this family, it is likely that the $\mathrm{BC}$ was a result of the pathogenic mutation c.IVS17$1 \mathrm{G}>\mathrm{A}$. The most interesting variant is c.4747_4749delATT, which produces the deletion of codon 1583, and corresponds to a novel variant with no BIC records and not described by other authors to date. This variant produces the deletion of isoleucine at position 1583 of the BRCA2 protein, which was found in a BC case diagnosed at age 32 with no family history of $\mathrm{BC}$ or OC, and was not detected in her healthy sister. Nevertheless, in her maternal lineage there are relatives with gallbladder cancer, early onset gastric cancer, leukemia and lung cancer cases. We cannot exclude the possibility that this mutation could be a pathogenic point mutation.

\section{DISCUSSION}

In the present study we conducted a screening for point mutations in the complete coding sequence of $B R C A 1$ and $B R C A 2$ genes in a group of 326 high risk families. Additionally, we analyzed LGR in both genes in a sample of 56 high-risk $\mathrm{BC}$ cases. Although there are some previous studies conducted in Hispanic American populations such as Mexico [13], Colombia [14], and Chile [10], this is the largest study conducted in high risk families in an Hispanic American population.

Evidences from different studies show that $3-50 \%$ of familiar BC cases are accounted for by mutations in BRCA1/2 [15]. Prevalence of BRCA1/2 mutations among high-risk cancer patients may vary by ethnicity and study inclusion criteria. In this study the frequency of $B R C A 1 / 2$ point mutations in the high-risk families was low (7.1\%). This percentage depends on the number of $\mathrm{BC}$ cancer in the family, the presence of $\mathrm{OC}$, and on the presence of male $\mathrm{BC}$. The highest frequency of BRCA1/2 mutations was found in families ( $\mathrm{n}=88)$ with 3 or more cases of BC or OC $(15.9 \%, 95 \%$ CI [8.3 - 23.6]), and $22.2 \%$ of the families ( $\mathrm{n}=9$ ) with one $\mathrm{BC}$ and one $\mathrm{OC}$ were carriers of BRCA1/2 mutations. Our results agree with those reported by other groups in Spanish and in Hispanic American populations. Diez et al. [16] reported 17\% (95\%CI 11.9 - 22.1) of BRCA1/2 mutation in the group of families with 3 or more BC cases ( $\mathrm{n}=206$ ). A study conducted in Chilean population by Gallardo et al. [10] reported a $25 \%$ mutation frequency in families with 3 or more BC cases (5/20 [95\% CI 6.0 - 44.0]) [14], and in Colombian population a $22.2 \%(95 \%$ CI 0 - 49.4) mutation frequency was found in families with $3 \mathrm{BC}$ cases $(\mathrm{n}=9)$ ). In Mexico, Ruiz-Flores et al. [13] reported that three of 17 (18\% [95\%CI 0 - 35.8]) site-specific BC families were carriers of BRCA1/2 mutations.

No BRCA1/2 pathogenic mutations were found in the group of early-onset $\mathrm{BC}$ patients ( $<35$ years), which suggests that this group of families are likely associated with other susceptibility genes. Previously, our group reported that in Chilean $\mathrm{BC}$ cases, the RAD51-135G>C polymorphism and the combined genotypes Thr/Met $-\mathrm{E} / \mathrm{G}(X R C C 3-\mathrm{T} 241 \mathrm{M}-R A D 51 D-$ E233G) were associated with an increased BC risk among women who (a) have a family history of $\mathrm{BC}$, (b) are BRCA1/2negative, and (c) were $<50$ years at onset. These findings also increased $\mathrm{BC}$ risk for $\mathrm{BC}$ cases diagnosed before 35 years and 
with no family history of BC and/or OC [17]. Also, Diez et al. [16] described low frequencies (2.6\%) of BRCA1/2 mutation for single women with $\mathrm{BC}$ and no family history.

We report four novel pathogenic mutations (two in BRCA1 and two in BRCA2). Three of them were reported in our previous study [9], and the BRCA2 c.9490delG mutation was described for the first time. The new mutation was found in the $\mathrm{BC} / \mathrm{OC}$ index case of a family that included other three $\mathrm{BC}$ cases and one prostate cancer case. The mutation was found in the index case who presented $\mathrm{OC}$ at age 42 and $\mathrm{BC}$ at age 50 and in her sister affected with $\mathrm{BC}$ at age 38 . We considered c.9490delG mutation to be a pathogenic mutation because it generates a truncated protein at codon 3088, deleting 330 aminoacids at its $\mathrm{C}$-terminus. The $\mathrm{C}$-terminal aminoacids are critical because the nuclear localization signals (NLSs) of $B R C A 2$ reside within the final 156 residues of BRCA2 [18]. The smallest known cancer-associated deletion of BRCA2 is predicted to remove 224 aminoacids (7\% of the coding sequence) from its C-terminus [19]. Previous reports have indicated that all of the known disease linked truncation of BRCA2 are likely to be non-functional because they do not translocate to the nucleus [18]. Therefore, the c.9490delG is probably pathogenic and disease associated.

\section{Recurrent mutations}

In our first screening of BRCAl/2 mutations in a sample of 64 high-risk BC and/or OC families from Chile we conclude that the BRCA gene mutation spectrum was heterogeneous and broad [9]. The present study found three recurrent mutations in BRCA1 (c.187_188delAG, c.2605_2606delTT, and c.3450_3453delCAAG) and three in BRCA2 (c.4969_4970insTG, c.5374_5377delTATG, c.6503_6504delTT), which contributed to $63.6 \%$ and $66.7 \%$ of all deleterious mutations in each gene respectively, that may reflect the presence of region-specific founder effects.

The contemporary Chilean population stems from the admixture of Amerindian peoples (Asians) with the Spanish settlers (European Caucasian) initiated in the $16^{\text {th }}$ and $17^{\text {th }}$ centuries. Later migrations $\left(19^{\text {th }}\right.$ century) of Germans, Italians, Arabs, and Croatians have had only a minor impact on the overall population (not more than $4 \%$ of the total population) and are restricted to the specific locations of the country where they settled [20]. The relationships among ethnicity, Amerindian admixture, genetic markers, and socioeconomic strata has been extensively studied in Chile [21-23].

The most prevalent mutation in BRCAl was c.3450_3453delCAAG. This frameshift mutation deletes the SQ sequences known as SQ-cluster domain (SCDs) that are the preferred sites of ATM phosphorylation. It also deletes the entire C-terminal region that includes two regions known as the BRCT domains. They are involved in DNA repair pathways and bind to many proteins. The c.3450_3453delCAAG mutation was detected in three unrelated families. Two of these families presented five cases of $\mathrm{BC}$ and the third family presented only two $\mathrm{BC}$ cases but with early age at diagnosis (Table 3). According to data from BIC database, this mutation has been identified in Norwegian, Australian, British, Spanish, African,American and Colombian populations. Blesa et al. [24] detected this mutation in two (3.9\%) out of 51 high-risk families from Eastern Spain (Valencian Community). In Colombia the 3450_3453delCAAG mutation was the most commonly observed mutation in BRCA1, detected in $9.4 \%$ of the $\mathrm{BC} / \mathrm{OC}$ cancer families from this country. The Chilean and Colombian populations have a high percentage of Hispanic admixture, and therefore the presence of the c.3450_3453delCAAG in both countries could be explained by a founder effect of Spanish origin.

The 2605_2606delTT was reported first by our group in the Chilean population as a novel BRCAl mutation [9]. To date, we have detected this BRCAl frameshift mutation in two Chilean families that also included cases with early age at diagnosis (Table 3). No BIC records or other description exist for this mutation. The affected families (F43 and F84) with the c.2605_2606delTT mutation had Chilean ancestry dating to many generations ago. Therefore, this mutation could have been present in the original Amerindian population that inhabited Chile prior to the colonization. 
The most prevalent mutation in BRCA2 was c.5374-5377delTATG. It was found in four families. In addition, it was detected in other two Chilean families in a previous report [10], for a total of six unrelated carrier families in the Chilean population. This 4-pb deletion is also the third most frequent BRCA2 mutation in Spain [16, 25, 26], and it was found in 6 of 59 (10.2\%) families from different geographic areas of this country. Three of these Spaniard families are from Castilla-Leon [27, 28]. Notably, the Spanish settlers that arrived in Chile in the $16^{\text {th }}$ century came mainly from Central Spain, specifically from the former kingdom of Castilla-Leon. Therefore, it is possible that the high prevalence of c.5374-5377delTATG in Chilean families may be a consequence of a founder effect of Spanish origin. The BRCA2 c.5374_5377delTATG mutation truncates the BRCA protein at codon 1732, disrupting 3 out of 8 BRC repeats that interact with RAD51, and the entire C-terminal region. Previous reports have indicated that BRCA2 is associated with an older age of diagnosis of BC [29]. On the contrary, in the Chilean families carriers of the c.5374_5377delTATG mutation the average age of BC onset is 42 years. Moreover, one of the positive families presents three cases with prostate cancer (Table 4).

The second recurrent mutation in BRCA2 is a 2-bp insertion of TG in nucleotide 4969 in exon 11 (c.4969_4970insTG), and it leads to a premature termination at codon 1617. This frameshift mutation is predicted to result in a protein truncation at codon 1617, deleting 53\% of the protein. This mutation was previously described by Gallardo et al. [10] in an Italian/Chilean family. We detected this point mutation in two unrelated families. The affected families (F77 and F325, Table 4) had Chilean ancestry dating from many generations ago. Both families had cases with early age at diagnosis ( $\leq 40$ years), indicating a high penetrance of this mutation. Moreover the family F325 presents one case of prostate cancer diagnosed at age 35 . To our knowledge this mutation has not been described in other populations.

The spectrum of recurrent mutations identified in Chilean families differed completely from that of Hispanic families of predominantly Mexican origin from Southern California [30]. None of the six recurrent mutations identified in Hispanic families of predominantly Mexican origin in the USA were found in the Chilean families or in Hispanic families from Colombia [14], implying that the mutation spectra among Hispanic populations in South America and the USA may differ.

\section{Variants of unknown significance}

In our screening of the BRCA1/2 genes, we found fourteen variants of unknown significance, six in BRCA1 and eight in BRCA2 (Table 5). In 12 of the 13 families the variants of unknown significance were identified exclusively in healthy relatives, and therefore it was not possible to establish whether they were associated with the cancers present in the families. Only in family F239 the proband with BC was carrier of variant c.8381T >C, but her daughter who also had BC was not a carrier. In this family it is likely that the variant is not the genetic cause of the $\mathrm{BC}$. The most interesting variant was c.4747_4749delATT in exon 11 of BRCA2, which deletes isoleucine at position 1583 of the BRCA2 protein. The BRCA2 protein directly binds to human RAD51 through its eight BRC repeats located at the 5' region of exon 11 . The number, sequence and spacing between these motifs is conserved during vertebrate evolution, suggesting its functional relevance [31]. BRC3 and BRC4 (amino acids 1517 - 1551) repeats have the strongest interaction with RAD51 [32]. Pellegrini et al. [33] have solved the crystal structure of the BRC4 peptide sequence bound to the RAD51 protein. This structure demonstrates a series of hydrophobic and hydrophilic interactions involving the hairpin structure of BRC4. Contact between BRC4 and RAD51 is maintained from Leu1521 to Glu1548 of the BRC4 sequence. The c.4747_4749delATT mutation deletes a hydrophobic amino acid (isoleucine) at position 1583, near to BRC4. This mutation was found only in a BC case with no family history of BC or OC cancer but with early age at diagnosis. Considering that this mutation does not result in a protein truncation, it is not possible to classify it as pathogenic. Nevertheless, we cannot exclude the possibility that this mutation could be a pathogenic point mutation. Functional assays are necessary to determine how this mutation could affect critical BRC4 interaction sites. 


\section{Large genomic rearrangements}

To determine the impact of BRCA1/2 LGRs in Chilean population, 56 hereditary BC and/or OC Chilean families negative for small mutations were screened using the MLPA technique. This represents the first study to screen for LGRs in BRCA1/2 in Chile and South America. No LGRs were found in either BRCA1 or BRCA2. In different populations it has been reported that LGRs in BRCA1 account for $0-27 \%$ of all disease-causing mutations, while LGRs in BRCA2 are rare and play a minimal role in $\mathrm{BC} / \mathrm{OC}[34,35]$. The variation in reported percentages may be attributable to ethnicity, inclusion criteria or technique used for LGRs detection. In this study, the mutation analysis for LGRs in BRCA1 and BRCA2 was performed using MLPA, which is the most common technique for LGR detection in the BRCA genes. The literature recommends screening for LGRs in BRCA1 in families with multiple cases of $\mathrm{BC} / \mathrm{OC}$ and average age at diagnosis of 50 years or less. It is also recommended to screen for LGRs in BRCA2 in families with at least one case of male BC. In our study only 36 out of the 56 analyzed cases belong to families with at least three $\mathrm{BC} / \mathrm{OC}$ cases, five of which have $\mathrm{OC}$ cases in their families.

With respect to ethnicity, BRCA1/2 LGRs play little or no role in hereditary BC in Afrikaner [35], Finnish [36-38], French-Canadian [39], and Iranian [40] populations. The high proportion of LGRs detected in the Hispanic population of the USA can be explained by a single founder deletion of exons 9-12 [41]. In Spain, the frequency of LGRs affecting the BRCA1/2 genes have been estimated at around 2\% in BRCA1 and 1.5\% in BRCA2 in cases previously testing negative for BRCAl/2 point mutations [42]. In Asian populations, LGRs account for 3\% of case in Singapore [43] and 0.8\% in Korea [44]. In the Chilean group screened in this study, no LGRs were found (0/56) in either BRCAl or BRCA2. Is likely that such mutations play no role in $\mathrm{BC} / \mathrm{OC}$ or have a low frequency in the actual Chilean population.

\section{ACNOWLEDGEMENTS}

The authors thank the many families who participated in the research studies described in this article. We acknowledge the Breast Cancer Group of CONAC: Maria Teresa Barrios, Angelica Soto, Rossana Recabbarren, and Leticia Garcia; and Lorena Seccia for her technical assistance

We also acknowledge the financial support of Vicerrectoria de Investigacion y Desarrollo (VID) Universidad de Chile (ENL 10/04); and Corporacion Nacional del Cancer (CONAC)

This work has been partially supported by a UICC International Cancer Technology Transfer Fellowship (ICR/08/152) and with Federal funds from the National Cancer Institute, National Institutes of Health under Contract NO2-CO-41101; and was partially supported by a grant of the "Fondo de Investigación Sanitaria" from the Spanish Health Ministry: FIS 05/2181.

The authors declare that they have no competing interests. 


\section{REFERENCES}

1.Jemal A, Siegel R, Ward E, Hao Y, Xu J,Thun MJ (2009) Cancer statistics, 2009. CA Cancer J Clin 59:225-249.

2.Peralta O, Jorquera A, Rencoret C, Castillo CD, Solé J,Campodónico Y (1995) Cáncer de mama: resultados del programa de pesquisa y tratamiento del Servicio de Salud Central. Rev Chil Obstet Ginecol 60:417-425.

3. Departamento de Estadísticas e Información en Salud (2009). Mortalidad en mujeres, Chile, 2006. Ministerio de Salud de Chile. http://deis.minsal.cl/deis/salidas06/causas06.asp?temp=TODAS_EDADES_MUJ.htm. Accessed 14 May 2010

4.Prieto M (2006) Situación epidemiológica del cáncer de mama en Chile 1994-2003. Rev Med Clin Condes 17:142-148.

5.Easton D (2002) Familial risks of breast cancer. Breast Cancer Res 4:179-181.

6.Wooster R,Weber BL (2003) Breast and ovarian cancer. New Engl J Med 348:2339-2347.

7.Miki Y, Swensen J, Shattuck-Eidens D, Futreal PA, Harshman K, Tavtigian S, Liu Q, Cochran C, Bennett LM, Ding W, et al. (1994) A strong candidate for the breast and ovarian cancer susceptibility gene BRCA1. Science 266:66-71.

8.Tavtigian SV, Simard J, Rommens J, Couch F, Shattuck-Eidens D, Neuhausen S, Merajver S, Thorlacius S, Offit K, StoppaLyonnet D, et al (1996) The complete BRCA2 gene and mutations in chromosome 13q-linked kindreds. Nat Genet 12:333337.

9.Jara L, Ampuero S, Santibáñez E, Seccia L, Rodríguez J, Bustamante M, Martínez V, Catenaccio A, Lay-Son G, Blanco R, Reyes J (2006) BRCA1 and BRCA2 mutations in a South American population. Cancer Genet Cytogenet 166:36-45.

10.Gallardo M, Silva A, Rubio L, Alvarez C, Torrealba C, Salinas M, Tapia T, Faundez P, Palma L, Riccio ME, Paredes H, Rodriguez M, Cruz A, Rousseau C, King MC, Camus M, Alvarez M, Carvallo P (2006) Incidence of BRCA1 and BRCA2 mutations in 54 Chilean families with breast/ovarian cancer, genotype-phenotype correlations. Breast Cancer Res Treat 95:81-87.

11.Chomczynski P,Sacchi N (2006) The single-step method of RNA isolation by acid guanidinium thiocyanate-phenolchloroform extraction: twenty-something years on. Nat Protoc 1:581-585.

12.den Dunnen JT,Antonarakis SE (2000) Mutation nomenclature extensions and suggestions to describe complex mutations: a discussion. Hum Mutat 15:7-12.

13.Ruiz-Flores P, Sinilnikova OM, Badzioch M, Calderon-Garciduenas AL, Chopin S, Fabrice O, Gonzalez-Guerrero JF, Szabo C, Lenoir G, Goldgar DE, Barrera-Saldana HA (2002) BRCA1 and BRCA2 mutation analysis of early-onset and familial breast cancer cases in Mexico. Hum Mutat 20:474-475.

14.Torres D, Rashid MU, Gil F, Umana A, Ramelli G, Robledo JF, Tawil M, Torregrosa L, Briceno I,Hamann U (2007) High proportion of BRCA1/2 founder mutations in Hispanic breast/ovarian cancer families from Colombia. Breast Cancer Res Treat 103:225-232.

15.Fackenthal JD,Olopade OI (2007) Breast cancer risk associated with BRCA1 and BRCA2 in diverse populations. Nat Rev Cancer 7:937-948.

16.Diez O, Osorio A, Duran M, Martinez-Ferrandis JI, de la Hoya M, Salazar R, Vega A, Campos B, Rodriguez-Lopez R, Velasco E, et al (2003) Analysis of BRCA1 and BRCA2 genes in Spanish breast/ovarian cancer patients: a high proportion of mutations unique to Spain and evidence of founder effects. Hum Mutat 22:301-312.

17.Jara L, Dubois K, Gaete D, de Mayo T, Ratkevicius N, Bravo T, Margarit S, Blanco R, Gomez F, Waugh E, et al (2010) Variants in DNA double-strand break repair genes and risk of familial breast cancer in a South American population. Breast Cancer Res Treat. doi: 10.1007/s10549-009-0709-2

18.Spain BH, Larson CJ, Shihabuddin LS, Gage FH,Verma IM (1999) Truncated BRCA2 is cytoplasmic: implications for cancer-linked mutations. Proc Natl Acad Sci U S A 96:13920-13925.

19.Hakansson S, Johannsson O, Johansson U, Sellberg G, Loman N, Gerdes AM, Holmberg E, Dahl N, Pandis N, Kristoffersson U, Olsson H,Borg A (1997) Moderate frequency of BRCA1 and BRCA2 germ-line mutations in Scandinavian familial breast cancer. Am J Hum Genet 60:1068-1078.

20.Cruz-Coke R (1976) Origen y evolución étnica de la población chilena. Rev Med Chile 101:365-368.

21.Valenzuela CY,Harb Z (1977) Socioeconomic assortative mating in Santiago, Chile: As demonstrated using stochastic matrices of mother-child relationships applied to ABO blood groups. Soc Biol 24:225-233.

22.Valenzuela CY, Acuña M,Harb Z (1987) Gradiente sociogenético en la población chilena. Rev Med Chile 115:295-299. 
23.Valenzuela CY (1988) On Sociogenetic Clines. Ethol Sociobiol 9:259-268.

24.Blesa JR, Garcia JA,Ochoa E (2000) Frequency of germ-line BRCA1 mutations among Spanish families from a Mediterranean area. Hum Mutat 15:381-382.

25.Diez O, Gutierrez-Enriquez S,Balmana J (2010) Heterogeneous prevalence of recurrent BRCA1 and BRCA2 mutations in Spain according to the geographical area: implications for genetic testing. Fam Cancer 9:187-191.

26.Infante M, Duran M, Esteban-Cardenosa E, Miner C,Velasco E (2006) High proportion of novel mutations of BRCA1 and BRCA2 in breast/ovarian cancer patients from Castilla-Leon (central Spain). J Hum Genet 51:611-617.

27.Neuhausen SL, Mazoyer S, Friedman L, Stratton M, Offit K, Caligo A, Tomlinson G, Cannon-Albright L, Bishop T, Kelsell D, et al (1996) Haplotype and phenotype analysis of six recurrent BRCA1 mutations in 61 families: results of an international study. Am J Hum Genet 58:271-280.

28.Tonin PN, Mes-Masson AM, Futreal PA, Morgan K, Mahon M, Foulkes WD, Cole DE, Provencher D, Ghadirian P, Narod SA (1998) Founder BRCA1 and BRCA2 mutations in French Canadian breast and ovarian cancer families. Am J Hum Genet 63:1341-1351.

29.Infante M, Duran M, Acedo A, Perez-Cabornero L, Sanz DJ, Garcia-Gonzalez M, Beristain E, Esteban-Cardenosa E, de la Hoya M, Teule A, et al (2010) BRCA1 5272-1G>A and BRCA2 5374delTATG are founder mutations of high relevance for genetic counselling in breast/ovarian cancer families of Spanish origin. Clin Genet 77:60-69.

30. Weitzel JN, Lagos V, Blazer KR, Nelson R, Ricker C, Herzog J, McGuire C, Neuhausen S (2005) Prevalence of BRCA mutations and founder effect in high-risk Hispanic families. Cancer Epidemiol Biomarkers Prev 14:1666-1671.

31.Shivji MK, Venkitaraman AR (2004) DNA recombination, chromosomal stability and carcinogenesis: insights into the role of BRCA2. DNA Repair (Amst) 3:835-843.

32.Powell SN, Willers H, Xia F (2002) BRCA2 keeps Rad51 in line. High-fidelity homologous recombination prevents breast and ovarian cancer? Mol Cell 10:1262-1263.

33.Pellegrini L, Yu DS, Lo T, Anand S, Lee M, Blundell TL,Venkitaraman AR (2002) Insights into DNA recombination from the structure of a RAD51-BRCA2 complex. Nature 420:287-293.

34.Hansen TO, Jonson L, Albrechtsen A, Andersen MK, Ejlertsen B, Nielsen FC (2009) Large BRCA1 and BRCA2 genomic rearrangements in Danish high risk breast-ovarian cancer families. Breast Cancer Res Treat 115:315-323.

35. Sluiter MD, van Rensburg EJ (2010) Large genomic rearrangements of the BRCA1 and BRCA2 genes: review of the literature and report of a novel BRCA1 mutation. Breast Cancer Res Treat. doi: 10.1007/s10549-010-0817-z

36.Laurila E, Syrjakoski K, Holli K, Kallioniemi A, Karhu R (2005) Search for large genomic alterations of the BRCA1 gene in a Finnish population. Cancer Genet Cytogenet 163:57-61.

37.Pylkas K, Erkko H, Nikkila J, Solyom S, Winqvist R (2008) Analysis of large deletions in BRCA1, BRCA2 and PALB2 genes in Finnish breast and ovarian cancer families. BMC Cancer 8:146.

38.Lahti-Domenici J, Rapakko K, Paakkonen K, Allinen M, Nevanlinna H, Kujala M, Huusko P,Winqvist R (2001) Exclusion of large deletions and other rearrangements in BRCA1 and BRCA2 in Finnish breast and ovarian cancer families. Cancer Genet Cytogenet 129:120-123.

39.Moisan AM, Fortin J, Dumont M, Samson C, Bessette P, Chiquette J, Laframboise R, Lepine J, Lesperance B, Pichette R, et al (2006) No Evidence of BRCA1/2 genomic rearrangements in high-risk French-Canadian breast/ovarian cancer families. Genet Test 10:104-115.

40.Pietschmann A, Mehdipour P, Mehdipour P, Atri M, Hofmann W, Hosseini-Asl SS, Scherneck S, Mundlos S,Peters H (2005) Mutation analysis of BRCA1 and BRCA2 genes in Iranian high risk breast cancer families. J Cancer Res Clin Oncol 131:552-558.

41.Weitzel JN, Lagos VI, Herzog JS, Judkins T, Hendrickson B, Ho JS, Ricker CN, Lowstuter KJ, Blazer KR, Tomlinson G,Scholl T (2007) Evidence for common ancestral origin of a recurring BRCA1 genomic rearrangement identified in highrisk Hispanic families. Cancer Epidemiol Biomarkers Prev 16:1615-1620.

42.Del Valle J, Feliubadalo L, Nadal M, Teule A, Miro R, Cuesta R, Tornero E, Menendez M, Darder E, Brunet J, Capella G, Blanco I,Lazaro C (2009) Identification and comprehensive characterization of large genomic rearrangements in the BRCA1 and BRCA2 genes. Breast Cancer Res Treat. doi: 10.1007/s10549-009-0613-9

43.Lim YK, Lau PT, Ali AB, Lee SC, Wong JE, Putti TC,Sng JH (2007) Identification of novel BRCA large genomic rearrangements in Singapore Asian breast and ovarian patients with cancer. Clin Genet 71:331-342. 
44.Seong MW, Cho S, Noh DY, Han W, Kim SW, Park CM, Park HW, Kim SY, Kim JY,Park SS (2009) Comprehensive mutational analysis of BRCA1/BRCA2 for Korean breast cancer patients: evidence of a founder mutation. Clin Genet 76:152-160. 